\title{
Conservação in vitro de Erythrina velutina a partir de embriões zigóticos
}

\author{
Priscila Tavares Fonseca $^{{ }^{*}}$, Cristina Ferreira Nepomuceno ${ }^{2, a}$, Tecla dos Santos Silva ${ }^{1, b}$ \& José Raniere \\ Ferreira de Santana ${ }^{1, \mathrm{c}}$
}

${ }^{1}$ Unidade Experimental Horto Florestal - Laboratório de Cultura de Tecidos Vegetais, Universidade Estadual de Feira de Santana, Feira de Santana, Bahia, Brasil.

${ }^{2}$ Universidade Federal do Recôncavo da Bahia, Cruz das Almas, Bahia, Brasil.

\begin{abstract}
Resumo - Erythrina velutina é nativa da Caatinga, domínio fortemente impactado pela exploração de seus recursos naturais. Dessa forma, o objetivo deste trabalho foi avaliar a indução de brotos a partir de segmentos nodais de plantas germinadas in vitro, visando a conservação de E. velutina. No experimento I, sementes intactas e embriões zigóticos foram inoculados em meio de cultura WPM. Foram analisados então número de gemas, folhas e raízes, percentagem de germinação, comprimento da parte aérea e percentagem de plantas normais. No experimento II, os segmentos nodais de plantas oriundas da germinação de embriões zigóticos in vitro foram inoculados em meio de cultura WPM suplementado com BAP ou CIN $[0,0 ; 10,0 ; 20,0 ; 30,0$ e 40,0 $\mu \mathrm{M}]$. Foram avaliados então percentagem de explantes responsivos para formação de brotos, número de brotos e folhas, comprimento da parte aérea e a percentagem de formação de calos. O cultivo de embriões zigóticos proporcionou plantas mais vigorosas e uniformes, com maior número de gemas do que as obtidas a partir da germinação de sementes intactas. A concentração de $20 \mu \mathrm{M}$ de BAP é indicada para a regeneração de plantas oriundas de embriões zigóticos de E. velutina; com essa concentração, foi obtida uma média de 2,78 brotos/explante.
\end{abstract}

Palavras-chave adicionais: citocininas, cultivo in vitro, mulungu.

\begin{abstract}
In vitro conservation of Erythrina velutina from zygotic embryos) - Erythrina velutina is native from the Caatinga domain, which has been heavily affected by the exploitation of natural resources. Thus, the aim of this study was to evaluate the induction of buds from nodal segments of in vitro germinated plants, aiming at the conservation of E. velutina. In the experiment I, intact seeds and zygotic embryos were inoculated in WPM culture and the number of buds, leaves and roots, germination percentage, shoot length and percentage of normal plants were analyzed. In the experiment II, the nodal segments of plants from germination of zygotic embryos in vitro were inoculated in WPM culture supplemented with BAP and CIN [0.0, 10.0, 20.0, 30.0 and $40.0 \mu \mathrm{M}]$ and percentage of responsive explants to form buds, number of shoots and leaves, shoot length and the percentage of callus formation were analyzed. The cultivation of zygotic embryos provided more vigorous and uniform plants, with more gems than those obtained from the germination of intact seeds. The concentration of $20 \mu \mathrm{M}$ of BAP is indicated for the regeneration of plants from zygotic embryos of E. velutina; with this concentration, an average of 2.78 shoots/explant was obtained.
\end{abstract}

Additional key words: Cytokinins, in vitro culture, mulungu.

Erythrina velutina Willd. (Papilionoideae, Leguminosae), conhecida popularmente como bucaré, mulungu, mulungu-da-flor-vermelha, mulungu-da-floramarela, muchoco e mulungá, é uma árvore nativa nos estados da Bahia, Ceará, Maranhão, Minas Gerais, Paraíba, Pernambuco, Piauí, Rio Grande do Norte e Sergipe, ocorrendo preferencialmente em formações secundárias e apresentando dispersão irregular e descontínua (Carvalho 2008). Possui potencial econômico no setor madeireiro, artesanal (uso das sementes), tintorial (uso das flores), paisagístico e medicinal (uso de cascas e frutos) (Carvalho 2008), e devido a essa relevância econômica e ao extrativismo, tem sofrido reduções drásticas nos ambientes de ocorrência natural. Sua reprodução se dá por sementes, que apresentam dormência causada pela impermeabilidade do tegumento e, provavelmente, pela presença de inibidores da germinação (Carvalho 2008).

\footnotetext{
*Autora para correspondência: pristavares25@hotmail.com;

acfnbio@gmail.com; bsilva.stecla@gmail.com;

cjose.raniere@gmail.com

Editor responsável: Alessandro Rapini

Submetido: 8 dez. 2014; aceito: 29 jun. 2015

Publicação eletrônica: 7 out. 2015; versão final: 23 out. 2015
}

Sendo assim, suas sementes necessitam de escarificação para reduzir a desuniformidade e acelerar o processo germinativo (Santos et al. 2013). Aliado a este fato, essas sementes têm sido utilizadas para fins artesanais, o que pode estar comprometendo sua reprodução da espécie. Dessa forma, são necessárias técnicas de propagação e conservação que garantam a manutenção e a utilização de E. velutina de forma sustentável.

A conservação de recursos genéticos vegetais engloba um conjunto de atividades e políticas desenvolvidas para assegurar a existência e a contínua disponibilidade de plantas para fins diversos (Santos \& Salomão 2007). A maioria dos esforços de conservação ex situ tem sido feita com espécies cultivadas; entretanto, o desmatamento crescente tem aumentado a necessidade de se conservar espécies nativas, raras ou ameaçadas de extinção (Engelmann 2011). Técnicas de cultura de tecidos vegetais têm sido uma importante ferramenta para a multiplicação e conservação ex situ de germoplasma de espécies ameaçadas em decorrência do extrativismo e do uso indiscriminado. Surgem, então, alternativas que poderão contribuir para a propagação e conservação de E. velutina, assegurando a manutenção e o uso sustentável da espécie, visto que 
várias espécies já têm sido conservadas in vitro, dentre elas Cochlospermum regium (Schrank) Pilg. (Camillo et al. 2009), Piper hispidinervum C.DC. e Piper aduncum L. (Silva \& Scherwinski-Pereira 2011), Mandevilla velame (A.St.-Hil.) Pichon (Martins et al. 2011), Cannabis sativa L. (Lata et al. 2012), Asparagus racemosus Willd. (Ankita \& Animesh 2013) e Ipomoea batatas L. (Arrigoni-Blank et al. 2014).

A conservação in vitro possibilita a manutenção de um grande número de acessos num espaço pequeno, livre das intempéries e dos riscos que existem no campo, além de reduzir os custos, garantir a manutenção da fidelidade genética, facilitar a disponibilidade de material para o melhoramento genético e o intercâmbio de germoplasma (Faria et al. 2006), que pode ser realizado com a aplicação de crescimento lento. O crescimento lento consiste em reduzir drasticamente o metabolismo da planta sem afetar sua viabilidade. Essa redução pode ser induzida mediante estresse osmótico, redução da intensidade de luz ou temperatura, acréscimo de retardantes de crescimento, bem como reduzindo a concentração dos componentes salinos e orgânicos do meio de cultura (Withers \& Williams 1998), favorecendo a ampliação do tempo entre subcultivos e proporcionando menor custo para manutenção do banco de germoplasma in vitro (Canto et al. 2004).

A utilização de embriões zigóticos de E. velutina como fonte de explante inicial para a multiplicação e consequente conservação in vitro da espécie representa uma alternativa para assegurar a variabilidade genética da espécie. Entretanto, a aplicação dessa técnica requer o estabelecimento de protocolos eficientes de germinação e desenvolvimento (Lédo et al. 2007), bem como de multiplicação e regeneração in vitro de embriões zigóticos. São esses protocolos que darão suporte às fases posteriores da conservação in vitro, quando o material conservado terá que ser resgatado e sua capacidade de multiplicação e regeneração in vitro avaliada.

Para a multiplicação e regeneração de acessos conservados ex situ, o esperado é que a representatividade da variação genética contida na amostra inicial, que vem a ser a população de referência, seja mantida ao longo das gerações (Vencovsky et al. 2007). O estabelecimento de um protocolo de multiplicação, portanto, é parte fundamental quando se deseja a conservação de determinado material, pois é necessário garantir uma elevada taxa de recuperação de plantas a partir do germoplasma conservado in vitro. A regeneração in vitro, por sua vez, é promovida pela utilização de reguladores de crescimento, como citocininas e auxinas. Embora as citocininas tenham sido descobertas como fatores de divisão celular, quando aplicadas às plantas superiores podem estimular ou inibir uma variedade de processos fisiológicos, metabólicos, bioquímicos e de desenvolvimento (Taiz \& Zeiger 2009). A utilização mais frequente das auxinas é verificada na indução do desenvolvimento de nós, formação de calo e desenvolvimento de raízes adventícias (Carvalho \& Vidal 2003). Um balanço alto/baixo de auxinas/citocininas favorece $o$ enraizamento, enquanto um balanço inverso promove a formação da parte aérea, e concentrações iguais promovem a produção de calos (Guerra \& Nodari 2006).

No presente trabalho, foram induzidos brotos a partir de segmentos nodais de plantas germinadas de embriões zigóticos de Erythrina velutina. O objetivo deste estudo foi contribuir para a aplicação deste procedimento na conservação in vitro da espécie.

\section{MATERIAL E MÉtodos}

Local, material vegetal e meio de cultura. Os experimentos foram realizados no Laboratório de Cultura de Tecidos Vegetais (LCTV) da Universidade Estadual de Feira de Santana (UEFS), localizado no município de Feira de Santana, região do Semiárido da Bahia. Como explantes, foram utilizadas sementes de E. velutina coletadas na fazenda Caiçara, em Petrolina, Pernambuco, fornecidas pela Embrapa Semiárido e armazenadas no LCTV do Horto Florestal, sob temperatura ambiente.

Foi utilizado o meio de cultura WPM (Lloyd \& McCown 1980), acrescido de $87,64 \mathrm{mM}$ de sacarose e solidificado com $0,7 \%$ de ágar (HIMEDIA $®$ ). $\mathrm{O}$ pH do meio de cultura foi ajustado para $5,7 \pm 0,1$ antes da autoclavagem à temperatura de $121^{\circ} \mathrm{C}$ por 15 minutos. Os explantes foram inoculados sob condições assépticas, em tubos de ensaio $(25 \times 150 \mathrm{~mm})$ contendo meio de cultura e vedados com filme de Poli Cloreto de Vinila (PVC). As culturas foram mantidas em sala de crescimento com temperatura de $25 \pm 3^{\circ} \mathrm{C}$, sob fotoperíodo de $16 \mathrm{~h}$, umidade relativa de $60 \%$ e radiação fotossintética ativa de $60 \mu \mathrm{mol} \mathrm{m} \mathrm{m}^{-2} \mathrm{~s}^{-1}$, fornecida por lâmpadas fluorescentes branca-frias.

Germinação in vitro. Inicialmente, as sementes foram submetidas à escarificação mecânica (minirretífica Western ${ }^{\circledR}$ R-40) e desinfestação, conforme Costa et al. (2010). Elas foram lavadas em água corrente por $10 \mathrm{~min}$ e, em câmara de fluxo laminar, foram então desinfestadas com imersão em álcool a $70 \%$ por $1 \mathrm{~min}$. Em seguida, passaram por uma solução de hipoclorito de sódio $(\mathrm{NaOCl}$; água sanitária comercial - 2,5\% de cloro ativo) com duas gotas de detergente neutro por $15 \mathrm{~min}$ e foram lavadas quatro vezes em água destilada esterilizada.

Para a etapa de pré-embebição, as sementes foram acondicionadas em recipientes de $1000 \mathrm{~mL}$ contendo $500 \mathrm{~mL}$ de água destilada esterilizada, os quais foram vedados com filme PVC e mantidos em temperatura ambiente sob condições assépticas durante $20 \mathrm{~h}$. Posteriormente, parte das sementes foi utilizada para a retirada de embrião zigótico. Foi realizada uma incisão, 
cortando-as transversalmente no centro. Os cotilédones foram separados e o embrião zigótico retirado com uma pinça. A outra parte das sementes desinfestadas e pré-embebidas foram utilizadas intactas. Os embriões zigóticos e as sementes intactas foram então inoculados separadamente em tubos de ensaio contendo $15 \mathrm{~mL}$ de meio de cultura WPM.

O delineamento experimental foi inteiramente casualizado (DIC), com dois tratamentos (embriões zigóticos e sementes intactas) compostos por 6 repetições, cada uma delas com 5 unidades experimentais (um explante por tubo de ensaio). Após 30 dias, foram avaliadas: 1- percentagem de germinação, 2- número de gemas, 3- número de folhas, 4- comprimento da parte aérea, 5- percentagem de plantas normais (ausência ou crescimento atrofiado da parte aérea, ausência de expansão foliar) e 6- número de raízes.

Os resultados foram submetidos à análise de variância (ANOVA) e as médias comparadas pelo teste de Tukey, com nível de significância de 5\% para os fatores qualitativos. As análises foram realizadas no programa SISVAR (Ferreira 2011).

Regeneração in vitro. Segmentos nodais (ca. $1 \mathrm{~cm}$ compr.) oriundos de plantas germinadas in vitro a partir de embriões zigóticos com 30 dias de idade foram inoculados verticalmente em tubos de ensaio contendo $10 \mathrm{~mL}$ de meio de cultura WPM, suplementado com concentrações isoladas $(0,0 ; 10,0$; $20,0 ; 30,0$ e $40 \mu \mathrm{M})$ das citocininas benzilaminopurina (BAP) ou cinetina (CIN).

O delineamento estatístico foi em DIC, com arranjo fatorial $2 \times 5$ (citocininas $\times$ concentrações de citocininas), sendo duas citocininas (BAP e CIN) e cinco concentrações $(0,0 ; 10,0 ; 20,0 ; 30,0$ e $40 \mu \mathrm{M})$, totalizando 10 tratamentos, com 5 repetições, cada qual composta de 5 tubos de ensaio com um explante cada. Aos 30 dias de inoculação, foram avaliados: 1percentagem de explantes responsivos para a formação de brotos, 2- número de brotos, 3- número de folhas, 4comprimento da parte aérea e 5- percentagem de formação de calos.

Os dados obtidos foram submetidos à ANOVA e as médias comparadas pelo teste de Tukey, com nível de significância de $5 \%$ para os fatores qualitativos e ajustes usando as equações de regressão polinomial para os fatores quantitativos. A análise foi realizada utilizando o programa SISVAR (Ferreira 2011).

\section{RESUltados}

Germinação in vitro. A análise de variância revelou efeito significativo $(\mathrm{p}<0,05)$ para percentagem de plantas normais, e efeito altamente significativo $(\mathrm{p}<0,01)$ para o número de gemas. Para as demais variáveis (percentagem de germinação, número de folhas, comprimento da parte aérea e número de raízes) não houve efeito significativo ( $\mathrm{p}>$ $0,05)$.

A maior média $(88,33 \%)$ de plantas normais foi obtida a partir da germinação de embriões zigóticos, sendo essa média estatisticamente maior àquela obtida com sementes intactas (Figura 1A). O maior valor médio $(2,7)$ para o número de gemas também foi observado nas plantas obtidas a partir de embrião zigótico, sendo esse valor estatisticamente maior ao obtido a partir de sementes intactas (Figura 1B).

Regeneração in vitro. A análise de variância revelou efeito altamente significativo da interação 'citocinina $\times$ concentrações de citocininas' para a percentagem de explantes responsivos para a formação de brotos, o número de brotos e a percentagem de formação de calo. $O$ fator 'concentrações de citocininas' isolado teve efeito altamente significativo $(\mathrm{p}<0,01)$ na percentagem de explantes responsivos para formação de brotos, no número de brotos e folhas, no comprimento da parte aérea e na percentagem de
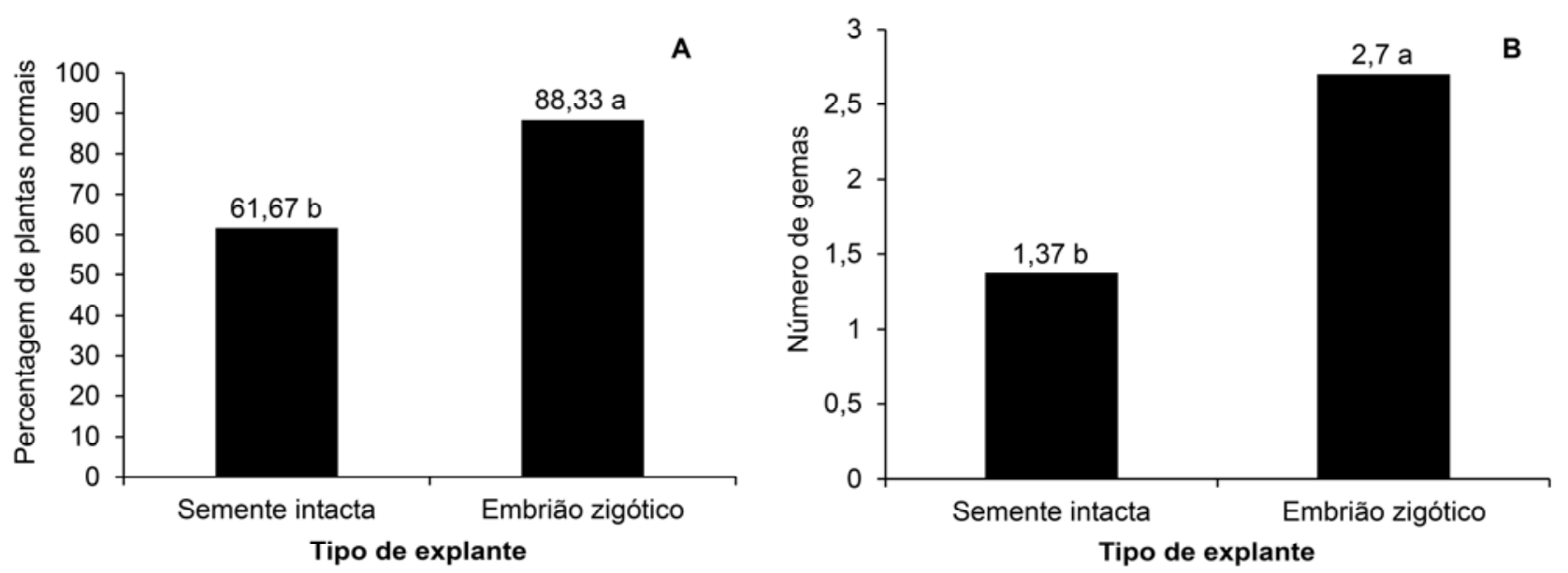

Figura 1. Percentagem de plantas normais (A) e número de gemas (B) obtidos de sementes intactas e embriões zigóticos de Erythrina velutina após 30 dias de inoculação em meio WPM (Médias seguidas pela mesma letra não diferem estatisticamente entre si no nível de 5\% de probabilidade pelo teste de Tukey). 
Tabela 1. Resumo da análise de variância para porcentagem de explantes responsivos para formação de brotos (\%ER), número de brotos (NB), número de folhas (NF), comprimento da parte aérea (CPA), porcentagem de formação de calo (\%CALO) em brotos de Erythrina velutina obtida com diferentes concentrações de BAP e CIN em meio de cultura WPM. FV- fonte de variação; GL- grau de liberdade.

\begin{tabular}{|c|c|c|c|c|c|c|}
\hline \multirow{2}{*}{$\mathrm{FV}$} & \multirow{2}{*}{ GL } & \multicolumn{4}{|c|}{ Quadrados médios } & \multirow[b]{2}{*}{$\%$ CALO } \\
\hline & & $\%$ ER & $\mathrm{NB}$ & $\mathrm{NF}$ & CPA & \\
\hline Tipo de citocinina $(\mathrm{T})$ & 1 & $512,0^{* *}$ & $3,49^{* *}$ & $2,43^{\mathrm{NS}}$ & $1272,60^{* *}$ & $4,500^{\mathrm{NS}}$ \\
\hline Concentração (C) & 4 & $4252,0^{* *}$ & $1,48^{* *}$ & $52,81^{* *}$ & $7947,90^{* *}$ & $11727,50^{* *}$ \\
\hline $\mathrm{T} \times \mathrm{C}$ & 4 & $1852,0^{* *}$ & $1,03^{* *}$ & $8,13^{\mathrm{NS}}$ & $90,00^{\mathrm{NS}}$ & $609,50^{* *}$ \\
\hline Resíduo & 40 & 140,0 & 0,14 & 4,04 & 86,37 & 141,50 \\
\hline $\mathrm{CV}$ & & 17,20 & 26,24 & 31,91 & 34,11 & 23,10 \\
\hline
\end{tabular}

${ }^{* *}$ Significativo no nível de $1 \%$ de probabilidade pelo teste F. ${ }^{\mathrm{NS}}$ Não significativo no nível de $5 \%$ de probabilidade pelo teste F.

formação de calo, ao passo que o fator 'citocinina' isolado apresentou efeito altamente significativo $(\mathrm{p}<$ $0,01)$ na percentagem de explantes responsivos para a formação de brotos, no número de brotos e no comprimento da parte aérea (Tabela 1).

A percentagem de explantes responsivos para formação de brotos apresentou um comportamento linear decrescente das concentrações de citocininas para a citocinina BAP e comportamento quadrático descendente para a citocinina CIN. A maior média observada $(100 \%)$ para esta variável foi atingida na ausência das citocininas (Figura 2A).

A análise de regressão para o número de brotos indicou um modelo quadrático ascendente das concentrações para a citocinina BAP e uma tendência linear crescente para a citocinina CIN. Como houve comportamento linear com a utilização da citocinina CIN, concentrações acima de $40 \mu \mathrm{M}$ ainda podem ser testadas (Figura 2B). A curva de resposta com BAP indicou que o uso de $21,03 \mu \mathrm{M}$ dessa citocinina atingiu o maior valor estimado para número de brotos $(2,35$ brotos/explante). No entanto, a maior média observada para esta variável $(2,78)$ foi obtida com $20 \mu \mathrm{M}$ de BAP (Figura 2B).

A adição de citocininas prejudicou o incremento de folhas nos brotos, pois o meio de cultura sem citocinina apresentou resultado estatisticamente superior aos demais tratamentos, atingindo valor médio de 9,72 folhas por explante (Figura 3A).

Analisando o efeito das concentrações de citocininas isoladamente, o modelo matemático que melhor se adequou ao comprimento da parte aérea foi o quadrático descendente, sendo os maiores brotos $(77,64 \mathrm{~mm})$ registrados na ausência das citocininas (Figura 4A). Ainda assim, dentre as duas citocininas testadas, a CIN se mostrou mais eficiente, apresentando um resultado estatisticamente superior ao obtido com BAP, produzindo brotos com média de 32,29 mm de comprimento (Figura 3B).

A análise de regressão mostrou comportamento quadrático ascendente para a percentagem de formação de calos na base do explante com a utilização de ambas citocininas testadas neste estudo e foi observado $100 \%$ de formação de calo com a utilização de $10 \mu \mathrm{M}$ de BAP (Figura 4B).

\section{DISCUSSÃo}

Ao analisar os dados experimentais, constatou-se que a testa parece ter agido como barreira à expansão foliar nas sementes intactas. Além disso, a liberação de exsudados durante o processo de pré-embebição e a inoculação das sementes em meio de cultura também podem ter promovido a ação de inibidores químicos. $\mathrm{O}$ processo de manutenção das sementes e inoculação em
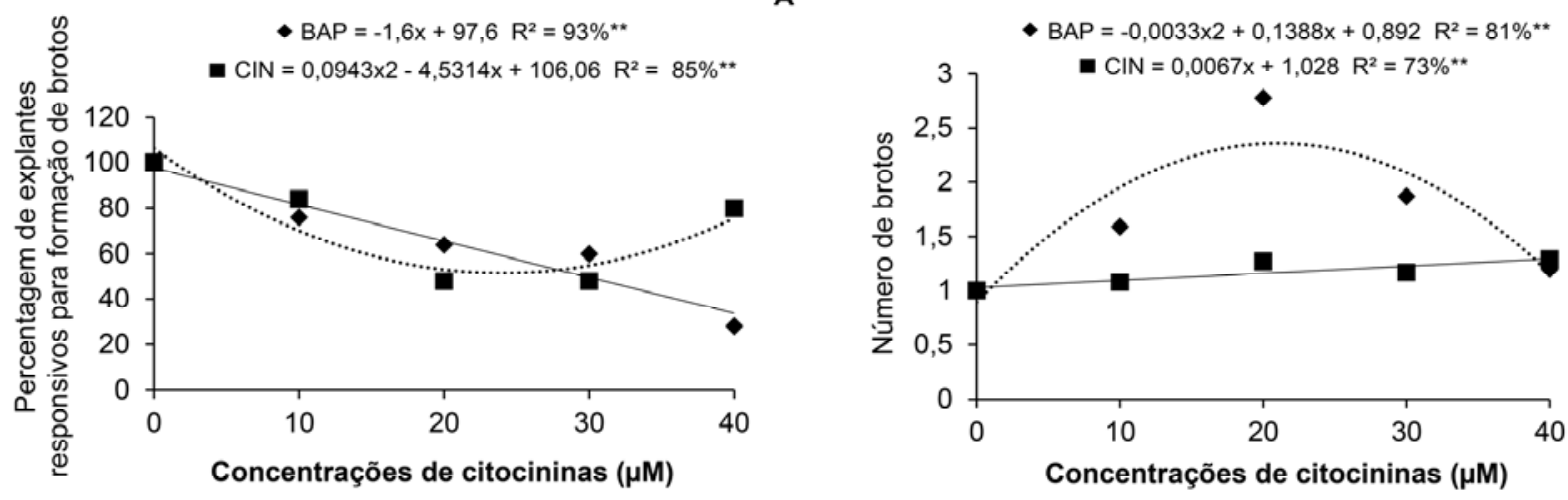

Figura 2. Percentagem de explantes responsivos para formação de brotos (A) e número de brotos em função de diferentes concentrações das citocininas BAP e CIN (B), obtidos a partir de segmentos nodais de Erythrina velutina após 30 dias de inoculação em meio WPM (** Significativo no nível de $1 \%$ de probabilidade pelo teste $\mathrm{F})$. 


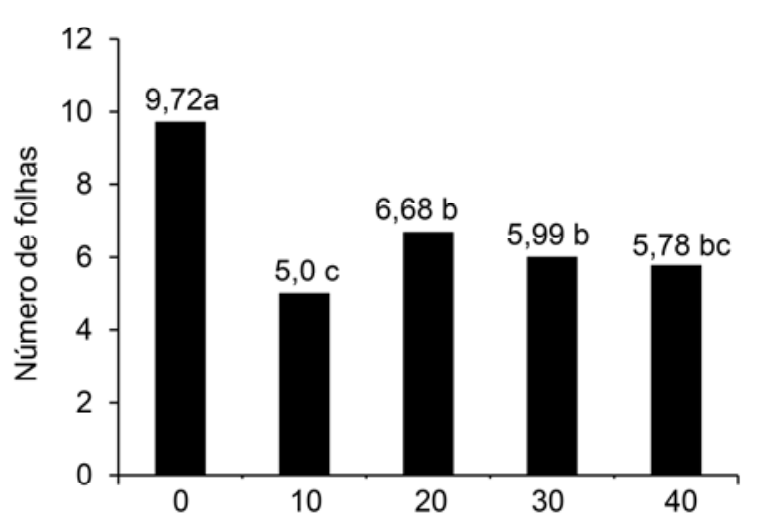

Concentrações de citocinina $(\mu \mathrm{M})$
A

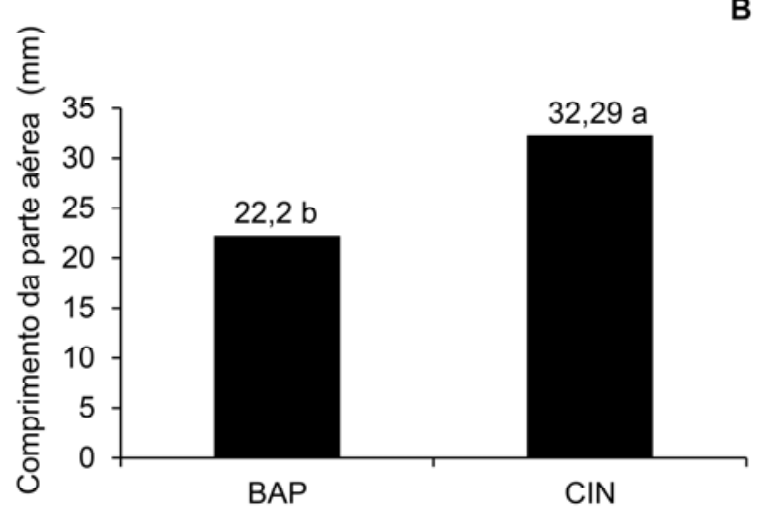

Citocininas

Figura 3. Número de folhas em função das concentrações de citocininas (A) e comprimento da parte aérea em função das citocininas BAP e CIN (B), obtidos a partir de segmentos nodais de Erythrina velutina após 30 dias de inoculação em meio de cultura WPM (médias seguidas pela mesma letra não diferem estatisticamente entre si no nível de $5 \%$ de probabilidade pelo teste de Tukey).

meio de cultura provavelmente reduziu o crescimento do eixo embrionário, pois a retirada do embrião zigótico e seu cultivo em meio de cultura levou à formação de plantas mais vigorosas. O mesmo foi observado por Fior et al. (2011), que registraram uma taxa elevada $(92 \%)$ de formação de plântulas in vitro de Butia capitata (Mart.) Becc. quando o opérculo da cavidade embrionária foi totalmente retirado, maior em relação às sementes sem escarificação.

O maior número de gemas observados nas plantas obtidas a partir de germinação de embrião zigótico está relacionado à formação de plantas vigorosas, uniformes, com menor alongamento do entrenó e crescimento mais lento, se comparado com as plantas advindas da germinação de sementes intactas, nas quais, visualmente, foi observado alongamento bem expressivo logo aos 15 dias de cultivo (dados não mostrados). Esse alongamento maior do entrenó e crescimento mais rápido das plantas procedentes de sementes intactas pode estar relacionado à produção de giberelinas pelo embrião não excisado durante o processo de germinação e à mobilização das reservas

\section{A}

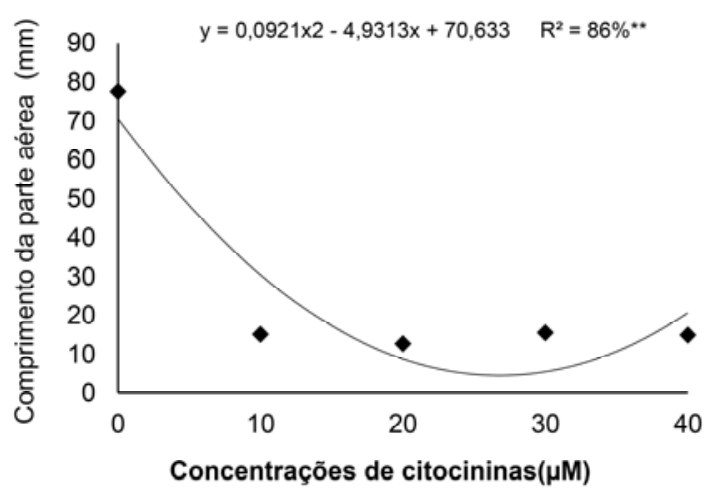

A cotiledonares. Este resultado corrobora Nepomuceno et al. (2007), que constataram um rápido crescimento in vitro de plântulas de Anadenanthera colubrina (Vell.) Brenan var. cebil (Griseb.) Altschul, causado pelo alongamento dos entrenós em função da giberelina endógena, sem que houvesse um aumento no número de entrenós. As giberelinas desempenham uma função importante na germinação, na quebra de dormência e no controle da hidrólise das reservas (Taiz \& Zeiger 2009). A mobilização das reservas cotiledonares também foi relatada para outras espécies lenhosas durante a germinação in vitro. Corte et al. (2006), por exemplo, observaram a redução no peso da matéria seca dos cotilédones de Caesalpinia peltophoroides Benth. durante a germinação e o crescimento inicial, associando está redução diretamente à diminuição dos compostos de reserva (lipídios, proteínas e carboidratos) nos cotilédones e ao aumento do peso da matéria seca da plântula. Oliveira et al. (1998) também notaram uma rápida diminuição do conteúdo de proteína cotiledonar solúvel durante a germinação e o crescimento de plântulas de Erythrina velutina.

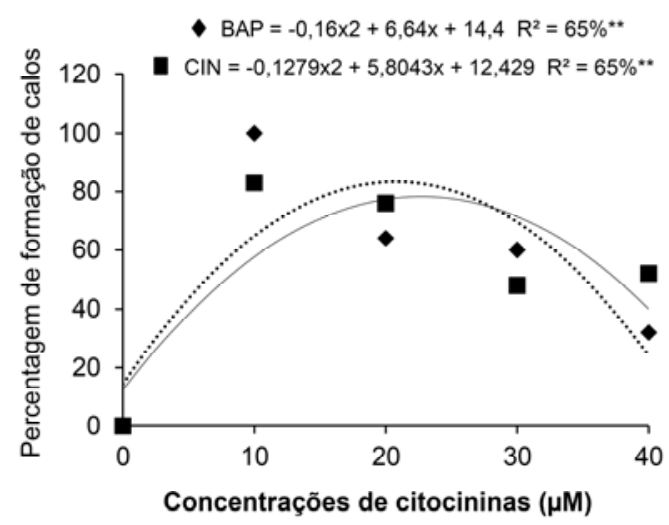

Figura 4. Comprimento da parte aérea em função das concentrações de citocininas (A) e formação de calo na base do explante em função das citocininas BAP e CIN (B) obtidos a partir de segmentos nodais de Erythrina velutina após 30 dias de inoculação em meio WPM ( ${ }^{*}$ Significativo no nível de $1 \%$ de probabilidade pelo teste $\left.\mathrm{F}\right)$. 
O crescimento rápido das plantas de E. velutina acelerou o processo de senescência, exigindo subcultivos em intervalos menores, não sendo vantajoso para sistemas de micropropagação, sobretudo quando se visa conservação in vitro. Nesse sentido, a utilização de embriões zigóticos no cultivo in vitro pode ser importante para a conservação, uma vez que eles possuem crescimento lento se comparados às plantas a partir de sementes intactas.

Durante a regeneração in vitro, o declínio linear na percentagem de explantes responsivos para a formação de brotos com a utilização de BAP provavelmente ocorreu pelo efeito fitotóxico provocado pelo aumento nas concentrações dessa citocinina, o que reduziu a capacidade de resposta organogênica do explante. $\mathrm{O}$ alto suprimento exógeno de citocininas pode ter aumentado a atividade da enzima citocinina oxidase, o que tende a desfavorecer a indução de brotações no explante; com isso, a citocinina deixaria de promover a divisão celular (Cid 2000; George 2008). Resultados diferentes foram observados por Gutiérrez et al. (2011), que obtiveram 97,33\% de explantes responsivos a partir de segmentos nodais de Bauhinia cheilantha (Bong.) Steud. nas maiores concentrações de citocininas $(8,88 \mu \mathrm{M}$ de BAP, 9,3 $\mu \mathrm{M}$ de CIN e 9,09 $\mu \mathrm{M}$ de TDZ), independentemente da citocinina testada. No entanto, a taxa responsiva para explantes de segmento nodal de Tapirira guianensis Aubl. também teve comportamento linear crescente em função do aumento das concentrações de BAP na ausência do ácido naftalenoacético (ANA) (Gutiérrez et al. 2013). Os mesmos autores concluíram, então, que concentrações superiores a $8,88 \mu \mathrm{M}$ ainda podem ser testadas. Segundo Dobránszki \& Silva (2010), a resposta do explante no processo de indução organogênica pode ser influenciada por vários fatores, como a concentração e os tipos de reguladores de crescimento, a idade do explante, o genótipo, as condições físicas do cultivo, a composição e a consistência do meio de cultura.

O maior número de brotos registrados com a adição de citocinina BAP em relação a CIN pode ser explicado pela maior atividade desta citocinina $(\mathrm{Hu} \&$ Wang 1983). A maior eficiência do BAP pode estar associada à capacidade dos tecidos vegetais metabolizarem os reguladores de crescimento naturais mais rapidamente do que os reguladores de crescimento sintéticos (Grattapaglia \& Machado 1998). No entanto, o número de brotos registrados no presente estudo foi inferior ao obtido por Costa et al. (2010) em culturas dessa mesma espécie, sendo o maior número de brotos $(2,68)$ em segmentos nodais oriundos de plantas germinadas a partir de sementes em meio WPM suplementado com 17,76 $\mu \mathrm{M}$ de BAP. Fermino Junior et al. (2014), em culturas de Tectona grandis, comparando os mesmos fatores (citocinina $x$ concentrações de citocininas), constataram que a concentração de $17,7 \mu \mathrm{M}$ da citocinina BAP apresentou um número maior de brotos $(3,63)$ em relação às demais citocininas testadas (CIN) e thidiazuron (TDZ).

A maior média no número de folhas de E. velutina foi observada na ausência das citocininas, diferindo dos resultados obtidos por Costa et al. (2010), que obtiveram o maior número de folhas $(9,4)$ no cultivo de segmentos nodais dessa mesma espécie quando 17,76 $\mu \mathrm{M}$ de BAP associado a $1,34 \mu \mathrm{M}$ de ANA foi acrescido ao meio de cultura WPM. Segundo eles (Costa et al. 2010), o incremento no número de folhas na etapa de multiplicação é bastante favorável, pois na inserção entre o caule e a folha existe a produção de gema, a qual poderá dar origem a um novo broto e, consequentemente, aumentar a produção de novas mudas, que é o objetivo primordial na fase de multiplicação in vitro.

$\mathrm{O}$ acréscimo de citocininas no meio de cultura reduziu a altura dos brotos, visto que as maiores médias foram observadas em meio de cultura sem citocinina. Esse comportamento pode ser explicado pela ação fisiológica das citocininas, as quais controlam a divisão celular, estando intimamente ligadas à diferenciação das células e sobretudo à formação de gemas caulinares (Kerbauy 2008), promovendo a quebra da dominância apical. Dessa forma, a adição de citocininas no meio de cultura refletiu diretamente na redução do tamanho dos brotos. Silva et al. (2013) também observaram uma redução no comprimento dos brotos de Caesalpinia pyramidalis Tul. com a suplementação de citocininas no meio de cultura, obtendo a maior média $(17,90 \mathrm{~mm})$ para comprimento da parte aérea em meio sem citocininas. Comportamento similar foi relatado por Kumar et al. (2010), os quais verificaram que o aumento de concentrações das citocininas BAP e CIN promoveu um decréscimo no comprimento dos brotos nos segmentos nodais de Chlorophytum borivilianum Sant. \& Fernandez, sendo o maior comprimento da parte aérea (48,0 e 43,0 $\mathrm{mm}$, respectivamente) também observado na ausência dos reguladores de crescimento. Soares et al. (2011), no entanto, obtiveram um comprimento maior $(45,5 \mathrm{~mm})$ da parte aérea de brotos oriundos de segmentos nodais de Harconia speciosa Gomes quando o regulador de crescimento BAP foi adicionado ao meio de cultura WPM, seguido pelos resultados com adição de CIN (34,6 mm) e de TDZ (31,3 mm).

A formação de calo na base do explante reportado nesse estudo, também tem sido relatada por outros autores como um dos muitos fatores que interferem negativamente na taxa de multiplicação de espécies lenhosas, como Acacia mearnssii Wild. (Borges Júnior et al. 2004), Peltophorum dubium (Spreng.) Taub. (Bassan et al. 2006), Bauhinia cheilantha (Bong.) Steud. (Gutiérrez 2010) e Caesalpinia echinata Lam. (Aragão et al. 2011). A adição de citocininas ao meio de cultura, mesmo em elevadas concentrações, pode favorecer balanços hormonais intermediários, o que estimula a divisão e a expansão celular, formando calos 
(Taiz \& Zeiger 2009). A formação de calos na base dos explantes pode gerar plantas com variação somaclonal e, de acordo com Phillips et al. (1994), esta variação é atribuída principalmente ao estresse imposto pelas condições de cultivo in vitro e à instabilidade cromossômica de células vegetais em cultura, manifestando-se como metilação do DNA, rearranjos de cromossomos e mutações pontuais. Essas variações são indesejáveis para protocolos de conservação, uma vez que geram mudanças no germoplasma que se deseja conservar.

A partir desses resultados, concluí-se que o estabelecimento in vitro de Erythrina velutina pode ser realizado a partir de embriões zigóticos, principalmente pelo crescimento lento das plantas geradas. A concentração de $20 \mu \mathrm{M}$ de BAP é indicada para a regeneração de plantas oriundas de embriões zigóticos de E. velutina, mas altas concentrações de citocininas podem levar à formação de variantes genéticos. Finalmente, ainda são necessários estudos para se elevar a taxa de recuperação do germoplasma a ser conservado a partir de embriões zigóticos.

\section{Agradecimentos}

Os autores agradecem à Universidade Estadual de Feira de Santana pelo aporte físico e à FAPESB pela concessão de bolsas.

\section{REFERÊNCIAS}

Ankita, P. \& Animesh, S. 2013. Effects of mannitol, sorbitol and sucrose on growth inhibition and in vitro conservation of germplasm of Asparagus racemosus - an important medicinal plant. Medicinal Plants - International Journal of Phytomedicines and Related Industries 5: 71-74.

Aragão, A.K.O.; Aloufa, M.A.I \& Costa, I.A. 2011. O efeito do BAP (6-benzilaminopurina) sobre a indução de brotos em explantes de pau-brasil. Cerne 7: 339-345.

Arrigoni-Blank, M.F.; Tavares, F.F.; Blank, A.F.; Santos, M.C.; Menezes, T.S.A. \& Santana, A.D.D. 2014. In vitro conservation of sweet potato genotypes. The Scientific World Journal 2014: 1-7.

Bassan, J.S.; Reiniger, L.R.S.; Rocha, B.H.G.; Severo, C.R.P. \& Flôres, A.V. 2006. Oxidação fenólica, tipo de explante e meios de cultura no estabelecimento in vitro de canafístula (Peltophorum dubium (Spreng.) TAUB.). Ciência Florestal 16: 381-390.

Borges Júnior, N.; Soborsa, R.C \& Martins-Coder, M.P. 2004. Multiplicação in vitro de gemas axilares de acácia-negra (Acacia mearnsii Wild.). Revista Árvore 28: 493-497.

Camillo, J.; Scherwinski-Pereira, J.E.; Vieira, R.F. \& Peixoto, J.R. 2009. Conservação in vitro de Cochlospermum regium (Schrank) Pilg. - Cochlospermaceae sob regime de crescimento mínimo. Revista Brasileira de Plantas Medicinais 11: 84-189.
Canto, A.M.M.E.; Souza, F.V.D.; Costa, M.A.C.; Souza, A.S.; Ledo, C.A.S. \& Cabral, J.R.S. 2004. Conservação in vitro de germoplasma de abacaxi tratado com paclobutrazol. Pesquisa Agropecuária Brasileira 39: 717-720.

Carvalho, F.M.J. \& Vidal, S.M. 2003. Noções básicas de cultura de tecidos. Embrapa: Documentos 116. Disponível em http://www.infoteca.cnptia.embrapa.br/bitstream/doc/273469/1/ DOC116.PDF; acesso em 22 fev. 2015.

Carvalho, P.E.R. 2008. Mulungu (Erythrina velutina). Embrapa: Circular Técnica 160. Diponível em http://www.infoteca.cnptia.embrapa.br/bitstream/doc/273469/1/ DOC116.PDF; acesso em 20 fev. 2015.

Cid, L.P.B. 2000. Auxinas. In: L.P.B. CID (ed.), Introdução aos Hormônios Vegetais. Embrapa Recursos Genéticos e Biotecnologia, Brasília, p. 55-81.

Corte, V.B.; Borges, E.E.L.; Pontes, C.A.; Leite, I.T.A.; Ventrella, M.C. \& Mathias, A.A. 2006. Mobilização de reservas durante a germinação das sementes e crescimento das plântulas de Caesalpinia peltophoroides Benth. Revista Árvore 30: 941-949.

Costa, G.M.; Nepomuceno, C.F \& Santana, J.R.F. 2010. Propagação in vitro de Erythrina velutina. Ciência Rural 40: 1090-1096.

Dobránszki, J. \& Silva J.A.T. 2010. Micropropagation of apple - a review. Biotechnology Advances 28: 462-488.

Engelmann, F. 2011. Use of biotecchnologies for the conservation of plant biodiversity. In Vitro Cell \& Developmental Biology, Gaithersburgg 47: 5-16.

Faria, G.A.; Costa, M.A.P.C.; Junghans, T.G.; Ledo, C.A.S \& Souza, A.S. 2006. Efeito da sacarose e sorbitol na conservação in vitro de Passiflora giberti N. E. Brown. Revista Brasileira de Fruticultura 28: 267-270.

Fermino Junior, P.C.P.; Raposo, A.; Nagao, E.O. \& Scherwinski-Pereira, J.E. 2014. Efeito de diferentes citocininas e sistema de cultura dupla-fase na micropropagação de Teca (Tectona grandis L.) estabelecida na Amazônia SulOcidental. Evidência 14: 7-20.

Ferreira, D.F. 2011. Sisvar: a computer statistical analysis system. Ciência e Agrotecnologia 35: 1039-1042.

Fior, C.S.; Rodrigues, L.R.; Leonhardt, C. \& Schwarz. S.F. 2011. Superação de dormência em sementes de Butia capitata. Ciência Rural 41: 1150-1153.

George, E.F. 2008. Plant tissue culture procedure - background. In: E.F. George, M.A. Hall \& G.-J. Klerk (eds), Plant Propagation by Tissue Culture: the background. Vol. 1. 3.ed., Springer, Dordrecht, p. 1-28.

Grattapaglia, D. \& Machado, M.A. 1998. Micropropagação. In: A.C. Torres, L.S. Caldas \& J.A. Buso (eds), Cultura de Tecidos e Transformação Genética de Plantas. EMBRAPA, Brasília, p. 183-260.

Guerra, M.P. \& Nodari, R.O. 2006. Apostila de Biotecnologia. Steinmacher, Florianópolis. Disponível em $<$ http://www.lfdgv.ufsc.br/Apostila\%20Biotecnologia.pdf $>$. Acesso em 15 ago 2011.

Gutiérrez, I.E.M. 2010. Micropropagação de Bauhinia cheilantha (Bong.) Steud. (Fabaceae). Dissertação de Mestrado. Universidade de Feira de Santana, Feira de Santana. 
Gutiérrez, I.E.M.; Nepomuceno, C.F.; Ledo, C.A.S. \& Santana, J.R.F. 2011. Regeneração in vitro via organogênese direta de Bauhinia cheilantha. Ciência Rural 41: 260-265.

Gutiérrez, I.E.M.; Nepomuceno, C.F.; Silva, T.S.; Fonseca, P.T.; Campos, V.C.A.; Alvim, B.F.M.; Carneiro, F.S.; Albuquerque, M.M.S. \& Santana, J.R.F. 2013. Multiplicação in vitro de Tapirira guianensis Aubl. (Anacardiaceae). Revista Ceres 60: 143-151.

Hu, C.Y. \& Wang, P.J. 1983. Meristem, shoot tip, and cultures. In: D.A. Evans, W.R. Sharp, P.V. Ammirato \& Y. Yamada (eds), Handbook of Plant Cell Culture. Vol. 1. MacMillan, New York, p. $177-227$.

Kerbauy, G.B. 2008. Fisiologia Vegetal. 2 ed. Guanabara Koogan, Rio de Janeiro.

Kumar, A.; Aggarwal, D.; Gupta, P. \& Reddy, M.S. 2010. Factors affecting in vitro propagation and field establishment of Chlorophytum borivilianum. Biologia Plantarum 54: 601-606.

Lata, H.; Chandra, S.; Mehmedic, Z.; Khan, T.A. \& EISohly, M.A. 2012. In vitro germoplasm conservation of high $\Delta^{9}$ tetrahydrocannabinol yielding elite clones of Cannabis sativa L. under slow growth conditions. Acta Physiologiae Plantarum 34: $743-750$.

Lédo, A.S.; Gomes, K.K.P.; Barboza, S.B.S.C.; Vieira, G.S.S.; Tupinambá, E.A. \& Aragão, W.M. 2007. Cultivo in vitro de embriões zigóticos e aclimatação de plântulas de coqueiro-anão. Pesquisa Agropecuária Brasileira 42:147-154.

Lloyd, G. \& McCown, B. 1980. Use of microculture for production and improvement of Rhododendron spp. HortScience 15: 415.

Martins, L.M.; Pereiras, A.M.S.; França, S.C. \& Bertoni, B.W. 2011. Micropropagação e conservação de Macrosyphonia velame (St. Hil.) Muell. Arg. em banco de germoplasma in vitro. Ciência Rural 41: 454-458.

Nepomuceno, C.F.; Rios, A.P.S.; Queiroz, S.R.O.D.; Pelacani, C.R. \& Santana, J.R.F. 2007. Controle da abscisão foliar e morfogênese in vitro em culturas de Anadenanthera colubrina (Vell.) Brenan var. cebil (Griseb) Altschul. Revista Árvore 31(5): 967-975.

Oliveira, J.T.A.; Moraes, S.M.D.; Cavada, B.S.; Moreira, R.A \& Vasconcelos, I.M. 1998. Protein and lecithin mobilization during Erythrina velutina forma aurantiaca seed germination and seedling growth in the dark. Revista Brasileira de Fisiologia Vegetal 10: 25-30.

Phillips, R.L.; Kaeppler, S.M. \& Olholt, P. 1994. Genetic instability of plant tissue cultures: Breakdown of normal controls. Proceeding of the National Academy of Sciences of the United States of America 91: 5222-5226.

Santos, I.R.I. \& Salomão, N.S. 2007. Criopreservação de germoplasma vegetal. In: L.L. Nass (ed.), Recursos Genéticos Vegetais. Embrapa Recursos Genéticos e Biotecnologia, Brasília, DF, p. 545-573.

Santos, L.W.; Coelho, M.F.B.; Azevedo, A.A.B.; Lima, A.K.B \& Souza, J.W.N. 2013. Erythrina velutina Willd. - Fabaceae: árvore de múltiplos usos no nordeste brasileiro. Revista Verde de Agroecologia e Desenvolvimento Sustentável 8: 72-80.

Silva, T.L. \& Scherwinski-Pereira, J.E. 2011. In vitro conservation of Piper aduncum and Piper hispidinervum under slow-growth conditions. Pesquisa Agropecuária Brasileira 46: 384-389.

Silva, T.S.; Nepomuceno, C.F.; Borges, B.P.S.; Alvim, B.F.M. \& Santana, J.R.F. 2013. Multiplicação in vitro de Caesalpinia pyramidalis (Leguminosae). Sitientibus série Ciências Biológicas 13: 1-6.

Soares, F.P.; Paiva, R.; Alvarenga, A.A.; Nery, F.C.; Vargas, D.P. \& Silva, D.R.G. 2011. Taxa de multiplicação e efeito residual de diferentes fontes de citocinina no cultivo in vitro de Hancornia speciosa Gomes. Ciência e Agrotecnologia 35: 152157.

Taiz, L. \& Zeiger, E. 2009. Fisiologia Vegetal. 4 ed. Artmed, Porto Alegre.

Vencovsky, R.; Nass, L.L.; Cordeiro, C.M.T. \& Ferreira, M.A.J.F. 2007. Amostragem em recursos genéticos vegetais. In: L.L. Nass (ed.), Recursos Genéticos Vegetais. Embrapa Recursos Genéticos e Biotecnologia, Brasília, DF, p. 233-234.

Withers, L.A. \& Williams, J.T. 1998. Conservação in vitro de recursos genéticos de plantas. In: C.A. Torres, L.S. Caldas \& J.A. Buso (eds), Cultura de Tecidos e Transformação Genética de Plantas. Vol. 1. Embrapa, Brasília, p. 297-329. 